\title{
Case studies of earthquake-induced effects on concrete channels*
}

\author{
Craig A Davis ${ }^{1, \uparrow}{\text { Jianping } \mathrm{Hu}^{1} \text { and Jean-Pierre Bardet }}^{2}$ \\ ${ }^{1}$ Los Angeles Department of Water and Power, Los Angeles, CA 90012, USA \\ ${ }^{2}$ Civil and Environmental Engineering Department, University of Southern California, Los Angeles, CA 90089, USA
}

\begin{abstract}
Case studies are presented for two concrete lined channels shaken by strong ground motions during the 1994 Northridge earthquake, the high speed channel (HSC) and bypass channel (BC), on the Los Angeles Department of Water and Power's Van Norman Complex. Performances of these two channels as they pass through different subsurface materials identify several important seismic aspects and the critical role of geotechnical earthquake engineering in assessing channel behaviors. Preliminary evaluations using detailed mapping of channel cracks, permanent ground movements, subsurface profiles, and nearby strong ground motion recordings from the 1994 earthquake show that the channel liners may have been damaged from both transient motions and permanent ground movements. Damage from permanent ground deformations is obvious by observation; therefore simplified analyses are presented only for transient movements. Site specific transient response analyses are performed to provide an initial assessment of the differing effects from transient and permanent ground movements on HSC and BC liner damage. These case studies are helpful for introducing the potential for lifeline damage from transient movements within zones of permanent ground movement, a concept not well understood in the earthquake engineering community.
\end{abstract}

Key words: concrete channel; ground motion; ground deformation; transient movement; lifeline CLC number: P315.9 Document code: A

\section{Introduction}

The seismic performance of concrete lined channels is not easy to predict because their behaviors are strongly dependant on interactions between the concrete liner and the soil or rock they are constructed within. Channels constructed in stable ground are expected to perform well during strong earthquake shaking; however those in marginally stable ground are susceptible to earthquake damage. This generalized behavior pattern is similar to that of other lifeline components, such as pipelines, but channel damage resulting from transient and permanent ground deformations is much more difficult to predict than the typical pipe performance due to greater dependency on seismic ground response, construction methodology, and channel structure geometry. Fragility studies for water supply conduits (American Lifelines Alliance, 2001) clearly identified this problem

\footnotetext{
* Received 3 July 2009; accepted in revised form 9 November 2009; published 10 February 2010 .

^ Corresponding author. e-mail: Craig.Davis@ladwp.com

(C) The Seismological Society of China and Springer-Verlag Berlin Heidelberg 2010
}

in predicting channel performance and also pointed out that a lack of case studies limits the ability to improve channel performance prediction.

To improve the understanding of channel seismic performance, this paper presents case studies of two concrete lined channels, the high speed channel (HSC) and the bypass channel (BC), that were severely shaken by the $M_{\mathrm{W}} 6.7$ Northridge earthquake on January 17 , 1994. The HSC and BC are located on the Los Angeles Department of Water and Power's (LADWP) Van Norman Complex (Complex) in the northern San Fernando valley.

\section{High speed channel (HSC) and by- pass channels (BC)}

Figures $1 \mathrm{a}$ and $1 \mathrm{~b}$ show the HSC round-bottomed triangular and $\mathrm{BC}$ trapezoidal cross sections, respectively. Figures 2 and 3 show HSC and BC profiles, respectively.

The HSC and $\mathrm{BC}$ were originally concreted using unreinforced concrete. In 1969, the HSC was enlarged to accommodate more water flow. The 1971 San Fernando 
earthquake caused severe damage to both channels. Channel repairs were made using wire mesh reinforced concrete gunite as shown in Figure 1. Specifications for the concrete used at different times is not available, but may reasonably be assumed to have at least a $13.8 \mathrm{MPa}$ compressive strength.

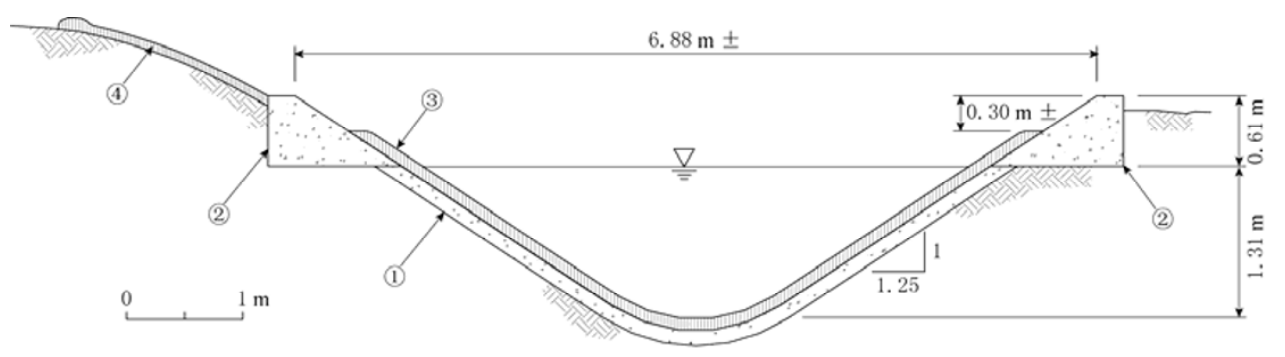

(a)

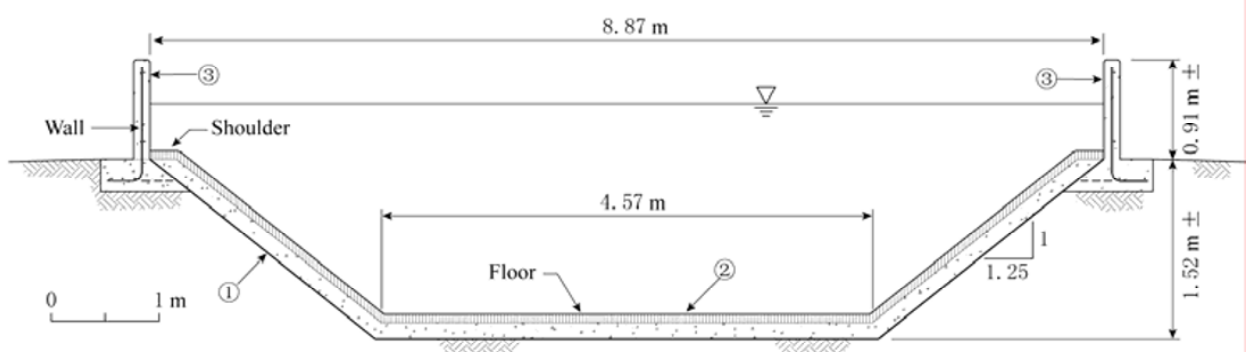

(b)

Figure 1 (a) High speed channel cross-section. (1) Original 1912 channel with $12.7 \mathrm{~cm}$ thick unreinforced concrete, (2) 1969 unreinforced concrete channel enlargement, (3) $7.6 \mathrm{~cm}$ thick wire mesh reinforced concrete gunite overly for post-1971 San Fernando earthquake repair, and (4) $7.6 \mathrm{~cm}$ gunite 1972 drainage improvement; (b) Bypass channel cross-section. (1) Original 1941 channel with $15.2 \mathrm{~cm}$ thick unreinforced concrete, (2) $7.6 \mathrm{~cm}$ thick wire mesh reinforced concrete gunite overly for post-1971 San Fernando earthquake repair, and (3) post-1971 earthquake channel enlargement.

\section{Subsurface conditions}

Soil profiles along the HSC and BC are presented in Figures 2 and 3. These profiles were determined using results of cone penetration testing (CPT) and boring logs obtained in the HSC and BC vicinity (Davis and Scantlin, 1997) with aid from the 1940 and 1913 (not shown) ground surface profiles. As seen in Figures 2 and 3, the soil conditions vary along the HSC and BC. Much of the soils consist of interbedded sandy silts, silty clay, and clay alluvial deposits, underlain by stronger alluvial soils above Saugus formation bedrock. In a few places the channels were constructed in fill. There are two zones of very weak clays, one under the HSC as shown in Figure 2, and one under the $\mathrm{BC}$ as shown in Figure 3.

Groundwater around the $\mathrm{HSC}$ and $\mathrm{BC}$ is influenced by water seeping from the channels, which are not considered to be water tight. The natural groundwater has a general downward gradient to the south along the HSC and southwest along the BC. Figure 2 shows the groundwater surface around the HSC measured from subsurface investigations within $10 \mathrm{~m}$ of the channel. Groundwater around to the $\mathrm{BC}$ was measured near the ground surface and is not shown in Figure 3. Seepage influences the groundwater elevation locally around both channels, causing a mound in the groundwater surface. Away from the channels the natural groundwater is approximately $6 \mathrm{~m}$ deep. Seepage from the BC influences natural water levels in the soft clay soils at distances greater than $18 \mathrm{~m}$. Seepage from the HSC dissipates rapidly within $10 \mathrm{~m}$ of the channel, except for a localized condition in soft clay soils where the groundwater is observed to remain near the ground surface.

\section{Channel performance during 1994 Northridge earthquake}

Figure 4 shows 1994 pipe and channel damage locations previously presented by Davis and Bardet (1995). As seen in Figure 4, most 1994 pipe and all channel damage occurred on the northern end of the Complex where the HSC and BC are located.

\subsection{Strong ground motinecordings of the North- ridge earthquake}

The 17 January 1994 Northridge earthquake with $M_{\mathrm{W}} 6.7$ occurred on an unmapped blind thrust fault (Wald 


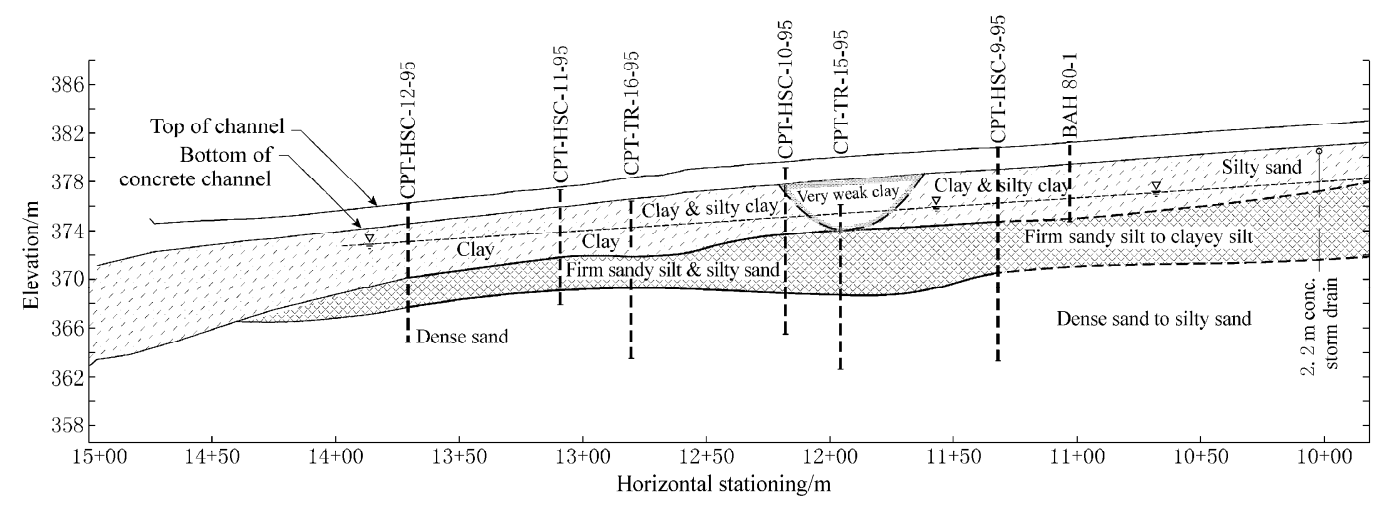

Figure 2 High speed channel profile showing CPT locations and interpreted subsurface soil conditions (1 stationing=50 m).

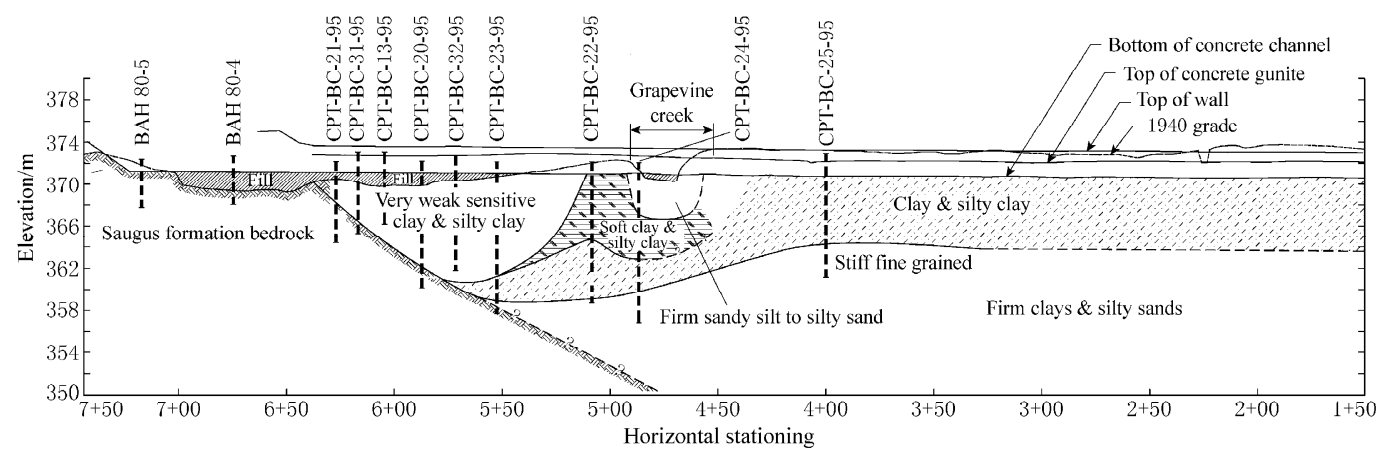

Figure 3 Bypass channel profile showing CPT locations and interpreted subsurface soil conditions (1 stationing =50 m).

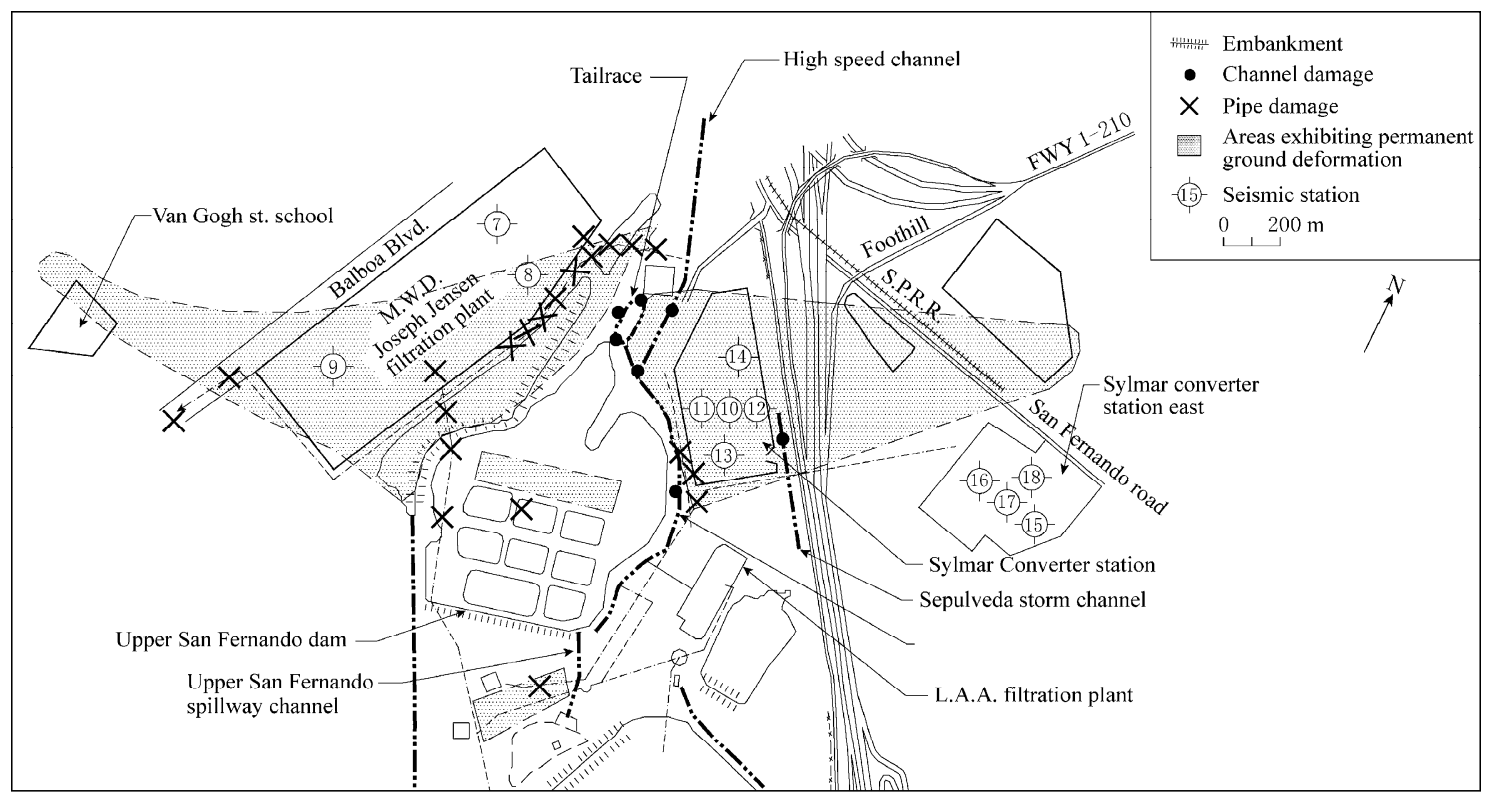

Figure 4 Northern Van Norman Complex area showing channel locations, seismic stations, and regions bounding observed permanent ground movement (shaded).

and Heaton, 1994) at an epicentral distance of approximately $11 \mathrm{~km}$ south of the Complex. Seismic stations 10 and 13 shown in Figure 4, located at the Sylmar Converter station a few meters east of the HSC and BC, are 
the most pertinent to this investigation (Bardet and Davis, 1996). Free-field station 10 recorded $0.90 \mathrm{~g}$ peak ground acceleration (PGA), $130 \mathrm{~cm} / \mathrm{s}$ peak ground velocity (PGV), and $41 \mathrm{~cm}$ peak ground displacement (PGD). The ground below station 10 consists of approximately $10 \mathrm{~m}$ of firm silty sand to sandy silt soil with an average shear wave velocity $\beta=263 \mathrm{~m} / \mathrm{s}$. Station 13 is located in a concrete building basement and recorded a $0.58 \mathrm{~g}$ PGA, $116 \mathrm{~cm} / \mathrm{s}$ PGV, and $38 \mathrm{~cm}$ PGD. The ground below station 13 consists of approximately $14 \mathrm{~m}$ of weak clayey silt with average $\beta=135 \mathrm{~m} / \mathrm{s}$. Firm Saugus formation has estimated $\beta=500-600 \mathrm{~m} / \mathrm{s}$; weathered rock $\beta$ is similar to firm soil at station 10 (i.e., $\beta=263 \mathrm{~m} / \mathrm{s}$ ).

\subsection{Channel damage}

Figures 5 and 6 present plots of crack density along the HSC and $\mathrm{BC}$, respectively. The crack density is defined as the length of cracks per unit channel length. Crack locations were surveyed and identified as greater than or less than $0.63 \mathrm{~cm}$ wide, referred to herein as major or minor cracks. Davis and Scantlin (1997) showed crack mappings and described the methods used to obtain the crack data. The channels were routinely inspected on an annual or semi-annual basis prior to the earthquake with no signs of significant pre-earthquake cracking. The post-earthquake cracks in both channels
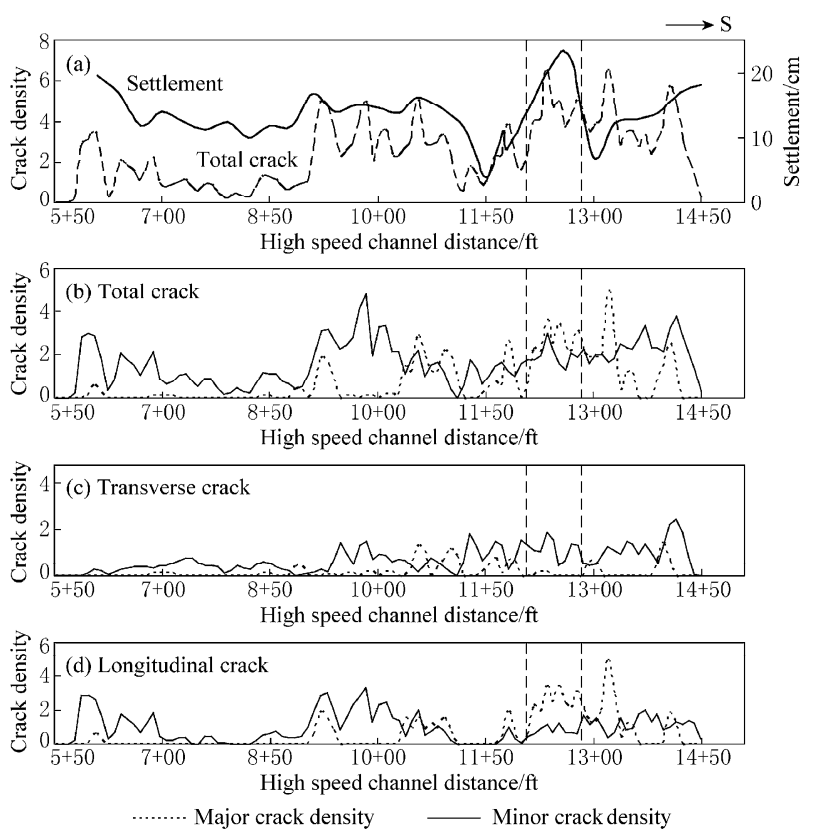

Figure 5 High speed channel settlement and crack density where two vertical dash lines indicate the area of observed horizontal movement. were mostly transverse (perpendicular) or longitudinal (parallel) to the channel axes. Some of the damage to both channels was due to the continued water flow across broken sections immediately following the earthquake. As shown in Figure 5c, the HSC sustained numerous transverse cracks. Many cracks extended through the original concrete liner and the gunite overlay that was placed in 1971. Most of the larger HSC longitudinal cracking identified in Figure 5d occurred at the top of the gunite overlay, indicating separation between the top curb and the channel.

The $\mathrm{BC}$ cracked and separated in many locations and in some places the overlay began to delaminate from the original channel. Figure 6 identifies the BC sustained numerous cracks. Davis et al (2002) described seven transverse cracks greater than $0.63 \mathrm{~cm}$ wide. Two cracks over $0.63 \mathrm{~cm}$ wide occurred near the south end over soil fill. Many transverse cracks over the clay soils are measured in excess of $1.3 \mathrm{~cm}$ wide. The greatest transverse cracking resulted above soft clayey soils between stations $5+30$ and $6+25$ rupturing across the entire channel section displacing the lining and walls. The two transverse cracks between stations $6+10$ and $6+25$ had a noticeable vertical offset, down to the north, and left lateral offsets having a minimum movement of $7.6 \mathrm{~cm}$.
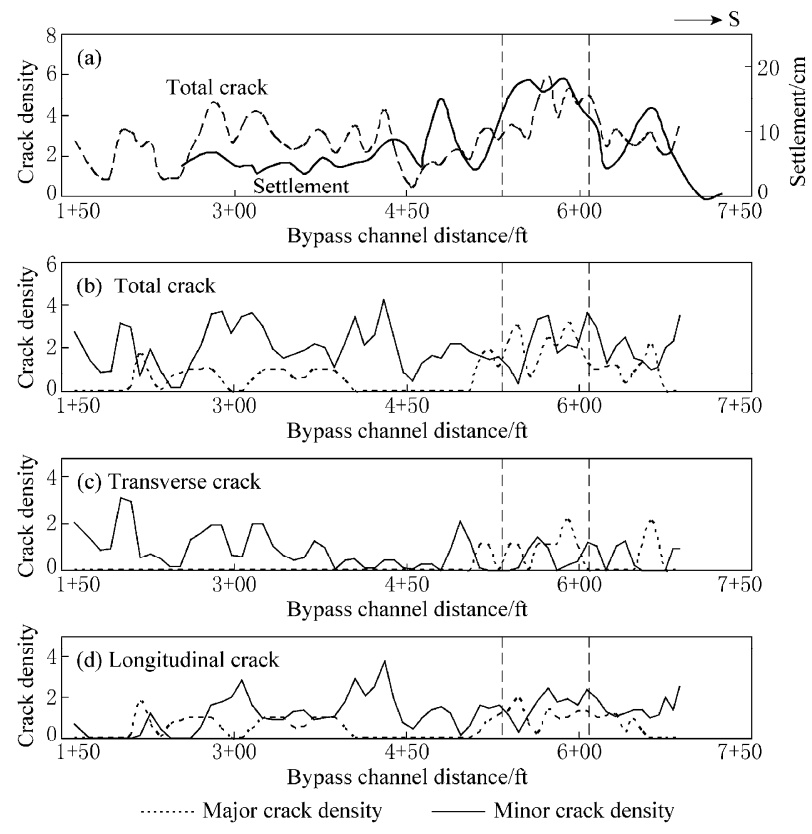

Figure 6 Bypass channel settlement and crack density where two vertical dash lines indicate the area of observed horizontal movement. 


\subsection{Permanent ground deformations}

Figures 5a and 6a show settlement profiles of the HSC and BC, respectively. All settlement measurements were taken on the concrete surfaces. In zones of large settlement, the channels could bridge the movement and create voids between the soil surfaces. As a result, settlement measurements reported in Figures 5a and 6a are considered a lower bound of deformation in the underlying soil. As seen in Figures 5a and 6a, the channels underwent large soil settlements with the greatest settlement, resulting in the regions corresponding to soft clayey soils shown in Figures 2 and 3. BC measurements showed differential settlements across the channel width of up to $0.15 \mathrm{~m}$, indicating the liner tilted down to the west. Figures 5 and 6 also show the approximate regions of observed greatest horizontal lateral permanent ground movement, which corresponds with the greatest settlement.

\section{Evaluation}

\subsection{Channel cracks}

Figures 5a and 6a present the calculated crack density using all cracks and show a general correlation of increased cracking with settlement, but no consistent pattern over the entire channel lengths. Figures 5 and 6 also show that the crack density magnitudes for any crack subcategory are similar for the HSC and BC. Figures $5 \mathrm{~b}$ to $5 \mathrm{~d}$ and $6 \mathrm{~b}$ to $6 \mathrm{~d}$ present the major and minor cracks and show a reasonably good correlation of major cracking with settlement, but no correlation of settlement with minor cracking. Longitudinal cracks in the HSC and transverse cracks in the BC are very well correlated with settlement and horizontal movement in Figures 5d and 6c, respectively. However, the HSC transverse and $\mathrm{BC}$ longitudinal cracks do not correlate well with permanent ground movements.

The minor cracks cannot be correlated with permanent horizontal or vertical ground movements, soil conditions, or channel type. The major cracks do correspond somewhat with larger permanent ground movements; however there are a number of $\mathrm{BC}$ longitudinal and HSC transverse major cracks that do not directly correlate with the permanent ground movements. Cracks not resulting from permanent ground strains were presumably caused by transient strains. As a result, most of the minor cracks and some of the major cracks are hypothesized to have occurred from transient motions through: (1) shear distortions transverse to channel cross-section, (2) horizontal wave propagation ground strain, and/or (3) differential ground motion along the channel alignment. In addition, this raises a question as to whether some cracks within the greatest permanent ground deformation regions resulted from transient motions before the permanent ground deformations occurred, in a manner similar to that observed on a nearby large diameter pipe (Davis, 2001). To start addressing this problem simplified analyses are performed for the three strain conditions mentioned above, each independent of the other.

\subsection{Simplified transient strain analyses \\ 5.2.1 Shear distortions}

Equivalent linear site response analysis using EERA (Bardet et al, 2000) was performed to better understand the horizontal shear distortion effects transverse to the channels. The analysis is performed at several HSC and BC locations. The subsurface profiles are defined in Figures 2 and 3. No site specific $G / G_{\max }$ and damping data are available for this study. The analysis uses standard $G / G_{\max }$ and damping curves for sand (Seed and Idriss, 1970; Idriss, 1990) and clay (Sun et al, 1988; Idriss, 1990) to describe the variation in shear modulus and damping ratio with shear strain amplitude. It provides preliminary result of possible surface strain. More detailed transient stain analysis using site response will require the site specific $G / G_{\max }$ and damping curve. In the calculations, soil layers were subdivided into sublayers of identical properties with the sublayer thickness $d$ satisfying $d \leq \beta / 5 f_{\max }$ (Bardet et al, 2000) where $f_{\max }$ is an acceptable higher cut-off frequency. The bedrock depth was estimated from limited field investigation information. The station 10 free-field motion is deconvolved to represent a bedrock input motion below the channels. The site response at station 13 was modeled and found to match closely with the earthquake recording.

Figures 7 and 8 show horizontal transient shear strain results at different locations along the HSC and $\mathrm{BC}$ in a direction transverse to the channel axes. These shear strain time histories are calculated, neglecting soil-structure interaction effects, at the depth between the ground surface and the channel bottom. As shown in Figure 7, between $\mathrm{BC}$ station $4+80$ and station $6+40$, the maximum transient shear strains in the first 10 seconds of shaking exceed $0.2 \%$, which is the assumed minimum strain to initiate concrete cracking (USACE, 1990). This correlates well with the observed major crack and settlements at this portion of the channel. It also indicates that some of the $\mathrm{BC}$ major cracks within the greatest 
permanent ground deformation regions may have resulted from transient motions independent of permanent ground deformations. As shown in Figure 8, similar
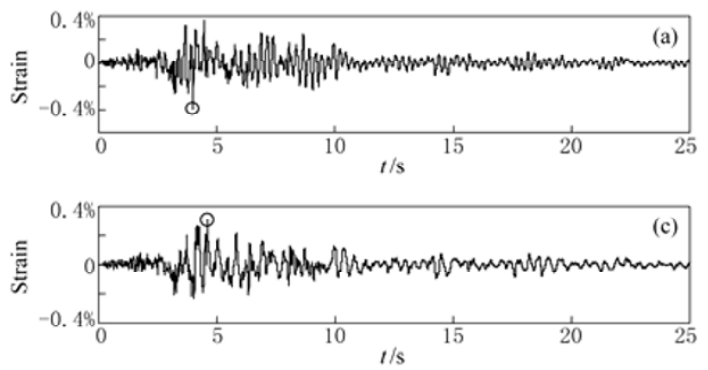

transverse strain correlations cannot be made for the HSC.
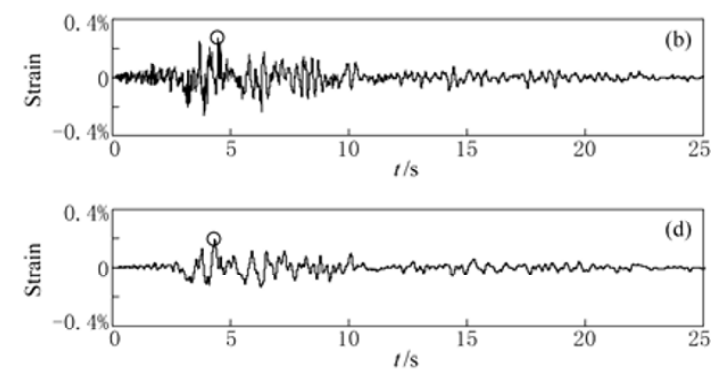

Figure 7 Transient shear strain at bypass channel with stations 6+25 (a), 6+10 (b), 5+95 (c) and 4+90 (d).
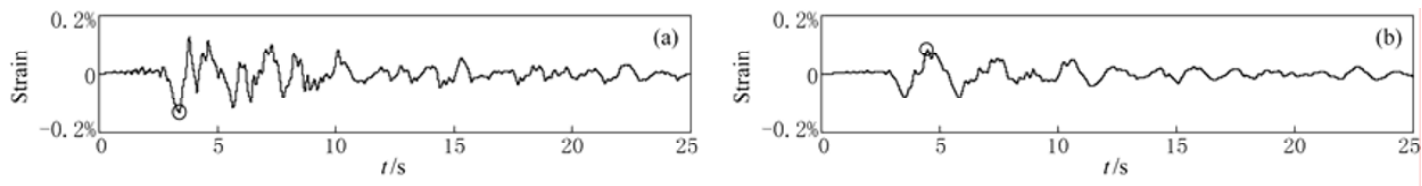

Figure 8 Transient shear strain at high speed channel with station $11+85$ (a) and station $13+10$ (b).

\subsubsection{Horizontal wave propagation}

The horizontal wave propagation ground strain can be estimated similar to that of pipes (O'Rourke and Hmadi, 1988) from $\varepsilon_{g}=v_{\mathrm{PG}} / C$ where $v_{\mathrm{PG}}$ is the value of PGV and $C$ is the apparent wave propagation velocity. The PGVs of the stations 10 and 13 were recorded nearly in line with the HSC and BC axes (Davis and Bardet, 2000). Assuming the PGV's result from Rayleigh surface waves and the apparent velocity $C=C_{\mathrm{ph}}=135-500 \mathrm{~m} / \mathrm{s}$, where $C_{\mathrm{ph}}$ is the phase velocity as described by O'Rourke and Hmadi (1988), then $\varepsilon_{g}=1 \%$ to $0.26 \%$, which is sufficient to cause channel cracking, especially on extensional wave cycles, anywhere along the HSC and BC alignment adequately bonded to the ground. $\varepsilon_{g}$ will change along the channel with wave length and as the subsurface conditions change, resulting in non-uniform channel cracking. However, where relatively uniform conditions exist similar periodic crack patterns should appear. This may explain the periodic crack density patterns in Figures 5 and 6.

\subsubsection{Differential ground motion}

A preliminary analysis to evaluate differential transient ground motion was also undertaken for the BC. The average transient strain $\gamma$ between two points on the channel is $\gamma=\left(\Delta_{1}-\Delta_{2}\right) / L$ where $\Delta_{i}$ is the ground surface displacement at location $i$ and $L$ is the distance between the two points. $\Delta_{i}=H \cdot v_{\mathrm{PG} i} / \beta_{i}$, where $H$ is the depth over which strain is evaluated. Figure 3 shows that the BC transits from bedrock having shallow fill cover to the weak clay soils at the station $6+40$. Bedrock site $i=1$ has $\beta_{1}$ ranging from $263 \mathrm{~m} / \mathrm{s}$ to $600 \mathrm{~m} / \mathrm{s}$ (average $432 \mathrm{~m} / \mathrm{s}$ ) and $v_{\mathrm{PG} 1}=130 \mathrm{~cm} / \mathrm{s}$ (estimated to be similar to station 10 ). Site $i=2$ is over the $12 \mathrm{~m}$ deep clay deposit at station $5+80$ having $\beta_{2}=135 \mathrm{~m} / \mathrm{s}$. Station 13 was recorded approximately over the deepest weak clay soils and is taken to represent motions at the station $5+80$, providing $\mathrm{V}_{\mathrm{PG}}=116 \mathrm{~cm} / \mathrm{s}$. Evaluating sites 1 and 2 for $H=12 \mathrm{~m}$ gives $\Delta_{2}=3 \Delta_{1}$. From the preceding information $\Delta_{2}=38$ $\mathrm{cm}$ at station $13, L=61 \mathrm{~m}$, and $\gamma=0.41 \%$. The strain resulting from differential ground motion is sufficient to cause major cracking. Similar results are expected for the HSC. This preliminary analysis assumes that the PGVs at sites 1 and 2 were in phase and occur at the same time. The transient ground strain may be greater or less than the average value depending on the phase of ground motion at sties 1 and 2 . The purpose of this preliminary analysis is to assess if this simplified method can estimate channel performances during earthquakes. These initial results indicate this simplified analysis may be able to reasonably predict concrete channel performance; however, more advanced transient analysis is needed to reveal the actual ground strain condition under the shaking to confirm applicability of the simple method.

Results from the three simplified strain evaluations provide initial indications that the $\mathrm{HSC}$ and $\mathrm{BC}$ were 
damaged from a combination of transient and permanent ground movements. Further work is needed to better understand how transient motions damage channels, appropriate methods for estimating damage for different channel types, and how to separate effects of transient and permanent movements.

\section{Conclusions}

Case studies of two concrete lined channels shaken by the 1994 Northridge earthquake were presented. Detailed investigations of subsurface conditions, earthquake damage, recorded site response, and permanent ground movements provide evidence that the channels were damaged by a combination of transient and permanent ground movements. Measured crack patterns do not consistently correlate with permanent ground movement locations or channel type. Simplified site specific response analyses were performed and provided initial indications that transient ground movements contribute to channel damage and combine with the permanent ground deformation in causing channel damage. The high speed (HSC) and bypass channel (BC) evaluations also showed that additional studies are required to fully understand the problem. These case studies provide insight into different effects from transient and permanent movements, valuable information to improve the understanding of channel seismic performance, and help identify needed geotechnical and lifeline research.

\section{References}

American Lifelines Alliance (ALA) (2001). Seismic Fragility Formulas for Water Systems. Parts I and II. A public-private partnership between the
Federal Emergency Management Agency (FEMA) and the American Society of Civil Engineers (ASCE). 2001-04-20, www.americanlifelinesalliance.org.

Bardet J P and Davis C A (1996). Engineering observations on ground motion at the Van Norman Complex after the Northridge earthquake. Bull Seism Soc Amer 86(1B): S333-S349.

Bardet J P, Ichii K and Lin C H (2000). EERA: A computer program for equivalent-linear earthquake site response analysis of layered soil deposits. Department of Civil Engineering, University of Southern California. 2004-07-06, http://gees.usc.edu/gees.

Davis C A (2001). Retrofit of large diameter trunk line case study of seismic performance. Proc. 2nd Japan-U.S. Workshop on Seismic Measures for Water Supply. American Water Works Association Research Foundation (AWWARF) and Japan Water Works Association (JWWA), Tokyo, Japan, August 2001.

Davis C A and Bardet J P (1995). Seismic performance of Van Norman water lifelines. Proc. 4th U.S. Conference on Lifeline Earthquake Engineering. ASCE, San Francisco, August 1995, 652-659.

Davis C A and Bardet J P (2000). Responses of buried corrugated metal pipes to earthquakes. J Geotech Eng Div, ASCE 126(1): 28-39.

Davis C A, Bardet J P and Hu J (2002). Effects of ground movements on concrete channels. Proc. 8th US-Japan Workshop on Eq. Resistant Design of Lifeline Facilities and Countermeasures against Soil Liquefaction. Tokyo, Japan, 16-18 December 2002.

Davis C A and Scantlin P S (1997). Response of high speed and bypass channels to 1994 Northridge earthquake and recommended repairs. Los Angeles Department of Water and Power Rpt. AX 215-47.

Idriss I M (1990). Response of soft soil sites during earthquakes. Proc. Memorial Symposium to Honor Professor Harry Bolton Seed. Berkeley, CA, II: 273-289.

Seed H B and Idriss I M (1970). Soil moduli and damping factors for dynamic response analysis. Report No. UCB/EERC-70/10, Earthquake Engineering Research Center. University of California, Berkeley, 48.

Sun J I, Golesorkhi R and Seed H B (1988). Dynamic moduli and damping ratios for cohesive soils. Report No. UCB/EERC-88/15, Earthquake Engineering Research Center. University of California, Berkeley, 42.

O'Rourke M J and Hmadi K E (1988). Analysis of continuous buried pipelines for seismic wave effects. Earthq Eng Soil Dynam 16: 917-929.

U.S. Army Corp of Engineers (USACE) (1990). Engineering and design settlement analysis. Engineer Manual, EM 1110-1-1904. U.S. Army Corps of Engineers, Washington D.C., 2-5.

Wald D J and Heaton T H (1994). A dislocation model of 1994 Northridge earthquake determined from strong ground motions. USGS Open-File Report, 94-278. 